\title{
Doodle Away: Exploring the Effects of Doodling on Recall Ability of High School Students
}

\author{
Deekshita Sundararaman ${ }^{1}$ \\ ${ }^{1}$ Round Rock High School, Texas, USA \\ Correspondence: Round Rock High School, Texas, USA. E-mail: deekshi01@gmail.com
}

Received: April 15, 2020

Accepted: May 7, 2020

Online Published: May 12, 2020

doi:10.5539/ijps.v12n2p31

URL: https://doi.org/10.5539/ijps.v12n2p31

\begin{abstract}
Doodling is often misinterpreted as a distraction to students in an academic setting- a hindrance to learning. However, recent research has shown that doodling may be beneficial to learning and memory retention. The current study expands upon previous research by investigating the impact of structured and unstructured doodling on auditory recall. This experiment was designed using a multi-method quantitative approach with an experiment that consisted of a control, structured doodling, and unstructured doodling group, and a questionnaire to assess students' doodling experience. A group of 39 high school juniors were chosen for this study. In all three conditions, students listened to a history lecture in their normal classroom circumstances and took a quiz over the information afterward. Students doodled in both experimental conditions- they shaded a structured doodling sheet in the first condition and doodled in a blank, white A4 sheet in the second condition. The results indicated that those in the structured and unstructured doodling group performed significantly better than those in the control group, with structured doodling scoring the highest out of the three. The Post Doodling Questionnaire indicated that the majority of students experienced less daydreaming and increased recall while doodling; furthermore, the majority of students reported doodling naturalistically.
\end{abstract}

Keywords: academic performance, cognition, doodling, learning, memory

\section{Introduction}

Your history professor starts lecturing about the French Revolution yet again and you find yourself thinking about your movie date on Saturday or what you're going to wear, only to realize that the lecture has come to an end and you did not retain a word of what he taught. This is a common scenario among high school students- daydreaming in moments of boredom. Engaging in task unrelated thoughts (TUTs), such as daydreaming (Note 1), is typical in situations where we are bored or detached from the stimuli, whether an academic, social, or business setting (Smallwood \& Schooler, 2006). It rarely ever happens when someone is concentrating on their work (Singer, 1966). To combat this boredom, people often begin chatting with their neighbors, playing with their phones, or doodling (Harris, 2000). Especially common among these activities is doodling.

According to the Oxford English Dictionary, doodling is defined as "an aimless scrawl made by a person while his mind is more or less otherwise applied." The definition itself is open for interpretation. For example, primary and secondary school teachers may attribute doodling with attention and learning, while many psychologists use their patients' doodles to understand their underlying psychological traits. Throughout history, many famous figures have found themselves sketching away. Twenty six out of forty four American Presidents doodled, from Ronald Reagan, who doodled cowboys and football players, to Theodore Roosevelt, who doodled animals and children, and John F. Kennedy, who doodled dominoes. Typically, these doodles are perceived as a sign of distraction- an indication that your mind was not where it was supposed to be. In academic settings, most school teachers condone this activity and state that it detracts attention from the lesson. However, the reality is quite the opposite. Doodling may actually not be an enemy of attention, but a friend.

\section{Literature Review}

Recent research has shown that doodling can actually improve memory retention (Andrade, 2010; Brown, 2011). In a surrogate doodling test devised by psychologist Jack Andrade, healthy volunteers were asked to listen to a monotonous telephone conversation and remember the names of people coming to a party. Out of all the 
volunteers, the volunteers that partook in a pencil-and-paper shading task simultaneously showed increased memory retention of the names. This is because doodling increases levels of arousal (Note 2), which most likely causes increased watchfulness to surrounding events (Schott, 2011).

Subsequently, Mariam Tadayon and Reza Afhami published a study in 2017 that examined the effects of doodling on junior high school students' learning. In their study, they demonstrated that compared to students who did not doodle, students who doodled outperformed non-doodlers in terms of educational performance. This conclusion is supported by various studies presenting that learning and learning-dependent performance can be improved when one engages in dual-tasks (Note 3), such as listening to lectures and doodling (Roche et al. 2007, Smallwood, O'Connor, Sudbery, \& Obonsawin, 2007). This is due to the relatively low amount of cognitive resources consumed by doodling, compared to daydreaming, which consumes a high amount of cognitive resources (Teasdale, Proctor, Lloyd, \& Baddeley, 1993). Daydreaming is typically associated with the high levels of arousal seen in boredom, through increased activity in 'default' cortical networks (Mason, Norton, Van Horn, Wegner, Grafton, \& Macrae, 2007; Smallwood et al., 2007b). The high levels of central executive resources it uses up is detrimental to tasks that compete for the same resources (Seibert \& Ellis, 1991; Smallwood, Baracaia, Lowe, \& Obonsawin, 2003; Smallwood, Fishman, \& Schooler, 2007). Conversely, doodling helps maintain optimal levels of arousal (Note 4), keeping people awake or reducing the high levels of autonomic arousal commonly associated with boredom (London, Schubert, \& Washburn, 1972). There have been a number of studies done on the role of doodling in preventing daydreaming and mind wandering. Looking into the study that was previously mentioned, researcher Jack Andrade tested subjects by requesting them to doodle while an auditory task was given. His results showed that doodlers unexpectedly retained more information compared to non-doodlers. Dr. Srini Pillay, an Assistant Professor of Psychiatry at Harvard Medical School who has analyzed Andrade's research, explains the benefits of doodling nicely:

"When you're bored, your fight-or-flight system will do all that it can to rally and stay alert. Doodling (a form of fidgeting) may be a last-ditch attempt at staying awake and attentive. Doodling keeps you from falling asleep, or simply staring blankly when your brain has already turned off. The permission to "free-draw" keeps your brain online just a little while longer. In addition, paying continuous attention places a strain on the brain, and doodling may be just the break your brain needs to keep attending without losing total interest."

A significant difference between previous experiments (Andrade 2010, Boggs, Cohen, Marchand, 2017) and Tadayon and Afhami's research is the amount of time that participants doodled and the setting. The former only doodled for a few minutes compared to the latter, who doodled for 10 class sessions that were 40 minutes each. Since the students had more time to doodle, they may have elicited a more naturalistic form of doodling, compared to those who only had a few minutes, who may have doodled forcefully due to the time constraint. Furthermore, the former utilized a recorded phone conversation, and the latter were situated in their regular classroom, listening to their teacher's lecture. This may have also played a part in the ability of students to elicit a more naturalistic form of doodling, which would have allowed them to pay more attention to the main task rather than focusing on doodling. Interestingly enough, the results between the unstructured doodling groups in Boggs' and Tadayon's studies showed a difference in recall- participants in the former recalled less information and participants in the latter recalled more information.

However, this is not the case for visual tasks. In a study conducted by Elaine Chan (2012), subjects were asked to doodle while a video task was given. Unlike auditory tasks, her experiment showed a negative correlation between doodling and performance on a visual recall task. These results indicate that doodling can only help students if it doesn't share a common cognitive source with the main activity. In visual tasks, both the primary task and doodling both require the use of the visual cortex, which may diminish the participants' concentration on the primary task. Other than visual recall tasks, doodling has generally shown to increase memory retention.

\subsection{Aims and Research Questions}

For the purpose of the current research, the effects of doodling on memory retention of auditory stimuli will be investigated by answering the following research question: To what extent does doodling during lectures improve recall ability in AP U.S. History students at a central Texas high school?

This study was guided by three hypotheses. First, it was hypothesized that both the structured and unstructured doodling groups would show increased recall ability than the control. Second, it was hypothesized that doodling would reduce the amount of daydreaming and/or mind-wandering experienced by students. Lastly, it was hypothesized that participants would elicit naturalistic forms of doodling in their regular academic setting and lesson durations. 


\subsection{Addressing Limitations}

There were a few limitations in the studies examined, and the main purpose of the present research is to extend their findings. The first limitation in Tadayon and Afhami's study is that it was only conducted on female junior high students. There is not only a difference between the educational performance between male and female students (Graber et al. 1997; Cavanagh et al. 2007; Sttatin \& David 1990), but there is also a difference in the amount of non-cognitive skills between the two, which affects their educational performance (Jacob 2002; Charles \& Luoh 2003; Dubas et al. 1991). Since the research is generalized to fit all junior high school students, recruiting only female participants may have impacted the scope of their results. An additional limitation of Afhami's study is the style in which the participants doodled. The students in their study participated in unstructured doodling (Note 5). Participants were instructed to doodle randomly on a sheet of paper, and the results were measured based on what percentage of the paper was filled with doodles. Although this is certainly a form of practical doodling, it lacks psychological validity. Participants who perform unstructured doodling are expected to exert various amounts of attention and other cognitive resources into their doodling activities (Boggs, Cohen, Marchand, 2017). For example, someone who is drawing a detailed doodle of an object or person uses more cognitive resources than someone who is simply shading in shapes. Thus it is possible that unstructured and structured (Note 6) doodling may produce varying results regarding the relationship between doodling and increased memory retention. The following study was designed to address some of the limitations in existing research about doodling. First, a representative population of high school students were recruited- a mix of female and male AP U.S. History students. This was aimed at producing research that was more representative of all high school students. Secondly, the impact of both structured and unstructured doodling was analyzed on the memory retention of high school students. Finally, the impact of longer doodling sessions was assessed on the type of doodling elicited by students by incorporating a questionnaire regarding students' doodling experience.

\section{Methods}

All experimental procedures were performed following informed consent for research participants in accordance with protocols approved by the Round Rock High School Institutional Review Board and have adhered to the Ethics Code of the American Psychological Association for protection of human subjects in scientific research.

\subsection{Research Design}

This study was conducted using a sequential multi method quantitative research design, which entails the application of two or more sources of data or research methods to the investigation of a research question. In the context of this experiment, two quantitative research methods were employed- a multi-factor within-subjects design and a survey regarding the participants' doodling experience.

The first phase, a multi-factor experimental design, consisted of one control and two experimental groups (structured and unstructured doodling). This was optimal to the study because it easily allowed the analysis of the differences between the control and treatment groups to see how scores improved or decreased over time. The within-subjects design made it easier to detect differences across levels of the independent variable because each subject's behavior under one condition is compared to that subject's behavior under the other condition. The second phase consisted of an online survey regarding the participants' doodling experience. In addition to the main experimental phase, which provided a general picture of the research problem, the survey helped explain the reasoning behind the results of the former, thereby strengthening the evidence.

\subsection{Participant Characteristics}

In order to conduct this study, a mixture of male and female students were recruited from a local high school. Since the students were not of legal age, they were given parent consent forms to verify that they were allowed to participate. Students were assured of anonymity and had the option of withdrawing from the experiment at any time. Participants of this study were 39 students (17 male, 22 female) from 5 different AP U.S. History classes at a central Texas high school. During the course of the experiment, they were between 16 to 17 years of age, with the mean age being 16.4. Experiment and control groups were respectively among doodlers and non-doodlers. It is to be noted that control and experimental groups used the same group of students, which was done specifically to minimize the impact of ethnicity, gender, and other external factors on the scores.

\subsection{Materials}

Throughout class, the students listened to a series of lectures and completed a quiz over the material. They completed a total of three quizzes, consisting of five short-answer questions each. All the quizzes were graded equally, with each question being 20 points, adding up to a total of 100 points for each individual quiz. 
Results were collected by the teacher who administered the quizzes, who recorded the students' scores on a copy of the gridded seating chart for each specific class. Each grid represented a seat, and the students' pretest and posttest quiz and test scores were written in their corresponding grid. It is to be noted that the control and experimental scores were written in different colors, which helped differentiate between the two.

Students in the first experimental group received pre-printed copies of a modified version of the "Structured Doodling Sheet" utilized by Boggs et al. (2017) before the lecture for doodling (see the appendix for structured doodling sheet). These doodling sheets were identical to those used in Boggs' experiment except for two additions to the top left-hand corner of the sheet- one blank for the student's seat number and one blank for their age. Students in the second experimental group received plain, white A4 sheets to doodle freely. Like the structured doodling sheet, the sheet had two blanks on the top left-hand corner of the sheet- one blank for the student's seat number and one blank for their age- which were used to ensure anonymity to differentiate between scores and find the mean age of the participants.

For the second phase of the study, all participants of the experiment were asked to fill out the online Post Doodling Experience Questionnaire (see the appendix for questionnaire) regarding their experience in doodling. The survey asked students about levels of daydreaming/mind-wandering, recall, and nature of doodling. There were three close-ended questions, with two answer choices for each-yes and no. These results served in strengthening the explanation behind the correlations found in the main experiment.

\subsection{Procedure}

After coordinating with the district and the school's AP U.S. History teacher, there was a consensus that the students would undergo a series of history lectures in the same place and the same circumstances. A period of time was allotted in the school year to run the experiment. Participants listened to one class period's worth of lecture, which ranged between 45 to 60 minutes. The students first took a quiz without doodling during lectures in their normal classroom setting, which was the control. It is to be noted that none of them were informed about the experiment at the time. These scores were recorded and used as the pretest. For the first experimental condition, the same participants were handed a structured doodling sheet, and were informed that they were suggested to shade in the shapes while listening to lectures. They were ensured that there was no obligation to doodle. After doodling throughout the lecture, the students turned in their doodling sheets, which were then assessed to see if they doodled or didn't doodle. The same procedure was repeated for the second experimental group, with the only difference being that they received a blank, white A4 sheet for unstructured doodling. The participants took a quiz over the information in the class after they doodled, out of which only the scores of the students who doodled were selected. These were used as the scores for experimental groups one and two (structured and unstructured doodling) respectively. After the experiment, all participants filled out the Post Doodling Experience Questionnaire online. Results of this survey were then collected and analyzed.

\section{Results}

\subsection{Experimental Results}

In order to analyze the variation between the quizzes, the one way repeated measures multivariate analysis of variance (one-way MANOVA) test was utilized. Based on Table 1, the averages of the control, structured, and unstructured doodling groups were $77.051(\mathrm{SD}=19.530), 92(\mathrm{SD}=10.342)$, and $85.410(\mathrm{SD}=8.415)$ respectively. As shown in Figure 1, there was a significant difference in the scores between the control and experimental groups- those in the structured and unstructured doodling groups scored significantly higher on the recall quiz, with the structured doodling group scoring the highest out of all three conditions (mean diff.=14.949). Table 2 ensures that the scores between groups were marginally significant. The F-value of 11.705 shows that the variance between the means of the pretest and posttest were significantly different. Furthermore, $p<.001$ which indicates that the data is not sampled from populations with the same mean, thus rejecting the null hypothesis. This supports my first hypothesis that both the structured and unstructured doodling groups would perform better than the control. 


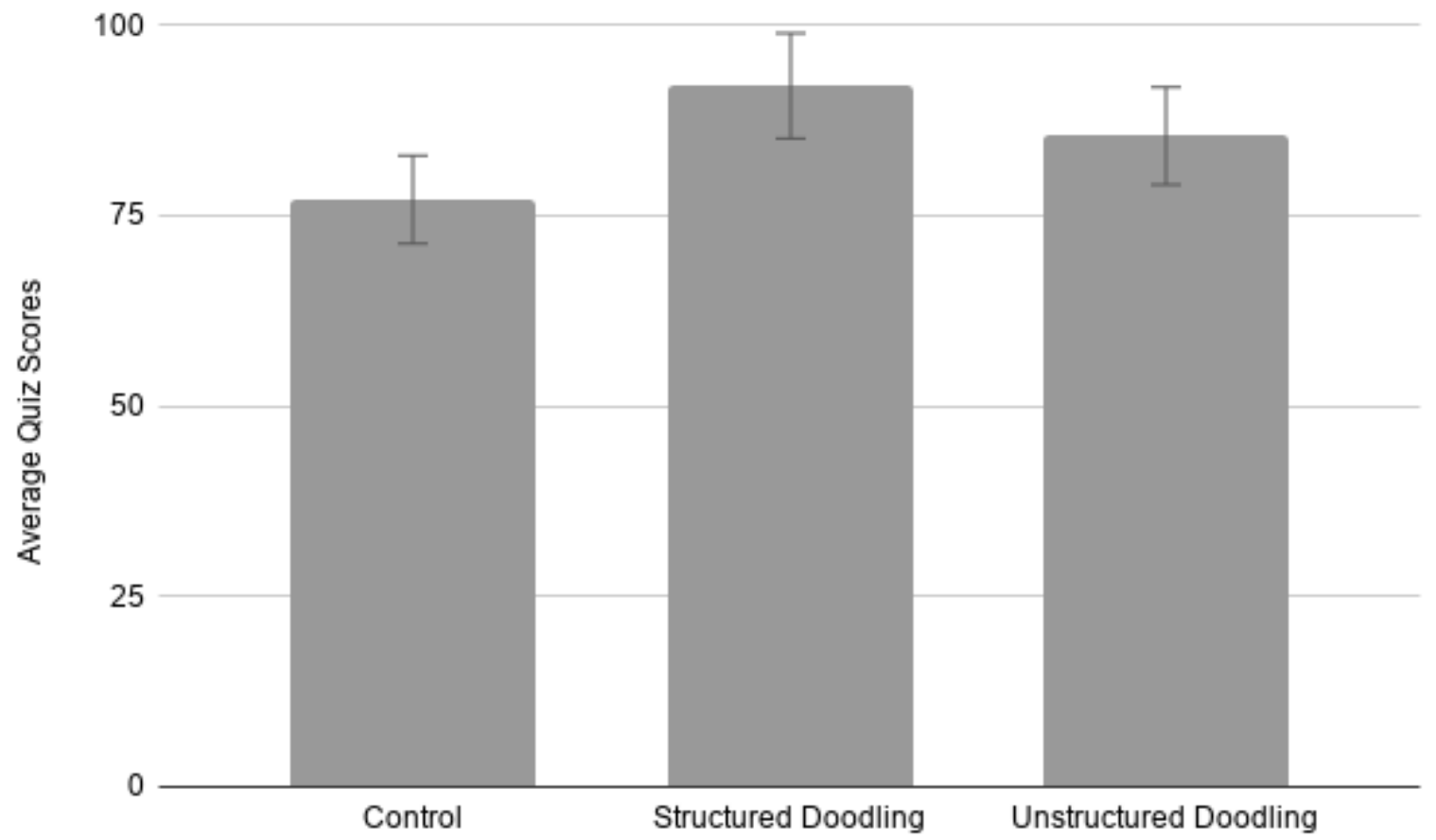

Figure 1. Performance data from the control and experimental groups. Standard errors are represented in the figure by the error bars attached to each column

Table 1. Measures of Central Tendency in Control and Experimental Groups

\begin{tabular}{ccccc}
\hline Groups & Count & Average & SD & Variance \\
\hline Control & 39 & 77.051 & 19.530 & 381.418 \\
Structured Doodling & 39 & 92.000 & 10.342 & 106.947 \\
Unstructured Doodling & 39 & 85.410 & 8.415 & 72.669 \\
\hline
\end{tabular}

Note. Standard deviation is abbreviated to "SD"

Table 2. MANOVA Summary

\begin{tabular}{ccccccc}
\hline Source of Variation & $S S$ & $d f$ & $M S$ & $F$ & $P$-value & F crit \\
\hline Between Groups & 4377.897 & 2 & 2188.949 & 11.705 & $<.001$ & 3.076 \\
Within Groups & 21319.333 & 114 & 187.012 & & & \\
Total & 25697.23 & 116 & & & & \\
\hline
\end{tabular}

\subsection{Post-Hoc Analyses}

Following the MANOVA, multivariate tests and multiple comparisons were run to further analyze quiz scores. As shown in Table 3, Wilk's $\lambda=.446, F(16,58)=1.806$, and $\mathrm{p}<.05$, indicating that the results are significant. The significant $\mathrm{F}$ shows that there are significant differences between the quiz scores of the control and experimental groups, showing that students' performance was dependent on doodling. Likewise, the results of the pairwise comparisons (Table 4) show that all of the comparisons between the control and experimental doodling groups are significant $(\mathrm{p}<.05)$, but the comparisons between the structured-unstructured and unstructured-structured doodling 
groups are not ( $>>05)$. This indicates that the two experimental groups significantly varied from the control group, but did not significantly vary between themselves.

Table 3. Multivariate Tests ${ }^{\mathrm{a}}$

\begin{tabular}{|c|c|c|c|c|c|c|}
\hline & Effect & Value & $F$ & Hypothesis df & Error $d f$ & Sig. \\
\hline & Pillai's Trace & .989 & $1278.811^{\mathrm{b}}$ & 2 & 29 & $<.0001$ \\
\hline & Wilks' Lambda & .011 & $1278.811^{\mathrm{b}}$ & 2 & 29 & $<.0001$ \\
\hline & Hotelling's Trace & 88.194 & $1278.811^{\mathrm{b}}$ & 2 & 29 & $<.0001$ \\
\hline \multirow[t]{4}{*}{ Intercept } & Roy's Largest Root & 88.194 & $1278.811^{\mathrm{b}}$ & 2 & 29 & $<.0001$ \\
\hline & Pillai's Trace & .658 & 1.841 & 16 & 60 & $<.05$ \\
\hline & Wilks' Lambda & .446 & $1.806^{\mathrm{b}}$ & 16 & 58 & $<.05$ \\
\hline & Hotelling's Trace & 1.011 & 1.769 & 16 & 56 & .06 \\
\hline Control & Roy's Largest Root & .654 & $2.451^{\mathrm{c}}$ & 8 & 30 & $<.05$ \\
\hline
\end{tabular}

a. Design: Intercept + Control

b. Exact Statistic

c. The statistic is an upper bound on F that yields a lower bound on the significance level.

\subsection{Questionnaire Results}

The results of the Post Doodling Experience Questionnaire are presented as a bar graph in Figure 2. The results present an explanation to strengthen the findings of the main experiment. First, $82.1 \%$ of students answered "yes" when asked if they experienced less daydreaming and mind-wandering during doodling compared to normal circumstances. Second, $79.5 \%$ of students answered "yes" when asked if they felt that they had increased recall ability after doodling. Third, 74.4\% answered "yes" when asked if they felt that they elicited naturalistic doodling, instead of forceful doodling.

The analysis of the results from the Post Doodling Experience are presented in Table 5. The answer "yes" equated to a score of 1 , while the answer "no" equated to a score of 0 . Based on the results, the average answer for whether students experienced less daydreaming/mind-wandering while doodling was 0.821 ( $\mathrm{SD}=0.061, \mathrm{p}<.001)$, showing that doodling is correlated to less daydreaming and/or mind-wandering. This supports my second hypothesis that doodling would reduce the amount of daydreaming and/or mind-wandering experienced by students. Likewise, the average answer for whether students experienced increased recall ability after doodling was $0.795(\mathrm{SD}=0.065$, $\mathrm{p}<.001$ ), showing that doodling is correlated with increased recall ability. This is analogous to the experimental results, which showed increased quiz scores in the experimental doodling groups. Finally, the average answer for whether participants felt that they elicited a naturalistic form of doodling was $0.744(\mathrm{SD}=0.070, \mathrm{p}<.001)$, which supports my last hypothesis that doodling in an academic setting under normal circumstances would enable participants to doodle naturalistically without constraint. 
Table 4. Multiple Comparisons

\begin{tabular}{|c|c|c|c|c|c|c|c|}
\hline & & & & & & $\begin{array}{r}95 \% \mathrm{Cc} \\
\text { Int }\end{array}$ & $\begin{array}{l}\text { fidence } \\
\text { val }\end{array}$ \\
\hline & (I) Treatment & (J) Treatment & $\begin{array}{c}\text { Mean Difference } \\
(I-J)\end{array}$ & $\begin{array}{l}\text { Std. } \\
\text { Error }\end{array}$ & Sig. & $\begin{array}{l}\text { Lower } \\
\text { Bound }\end{array}$ & $\begin{array}{l}\text { Upper } \\
\text { Bound }\end{array}$ \\
\hline & & $\begin{array}{l}\text { Structured } \\
\text { Doodling }\end{array}$ & $-14.94872 *$ & 3.09683 & $<.0001$ & -22.3028 & -7.5946 \\
\hline & Control & $\begin{array}{l}\text { Unstructured } \\
\text { Doodling }\end{array}$ & $-8.35897^{*}$ & 3.09683 & .022 & -15.7131 & -1.0049 \\
\hline & & Control & $14.94872 *$ & 3.09683 & $<.0001$ & 7.5946 & 22.3028 \\
\hline & $\begin{array}{l}\text { Structured } \\
\text { Doodling }\end{array}$ & $\begin{array}{l}\text { Unstructured } \\
\text { Doodling }\end{array}$ & 6.58974 & 3.09683 & .089 & -0.7643 & 13.9438 \\
\hline & & Control & $8.35897^{*}$ & 3.09683 & .022 & 1.0049 & 15.7131 \\
\hline $\begin{array}{l}\text { Tukey } \\
\text { HSD }\end{array}$ & $\begin{array}{l}\text { Unstructured } \\
\text { Doodling }\end{array}$ & $\begin{array}{l}\text { Structured } \\
\text { Doodling }\end{array}$ & -6.58974 & 3.09683 & .089 & -13.9438 & 0.7643 \\
\hline \multirow{11}{*}{ Scheffe } & & $\begin{array}{l}\text { Structured } \\
\text { Doodling }\end{array}$ & $-14.94872 *$ & 3.09683 & $<.0001$ & -22.6297 & -7.2678 \\
\hline & Control & $\begin{array}{l}\text { Unstructured } \\
\text { Doodling }\end{array}$ & $-8.35897^{*}$ & 3.09683 & .029 & -16.0399 & -0.678 \\
\hline & & Control & $14.94872 *$ & 3.09683 & $<.0001$ & 7.2678 & 22.6297 \\
\hline & $\begin{array}{l}\text { Structured } \\
\text { Doodling }\end{array}$ & $\begin{array}{l}\text { Unstructured } \\
\text { Doodling }\end{array}$ & 6.58974 & 3.09683 & .109 & -1.0912 & 14.2707 \\
\hline & & Control & $8.35897^{*}$ & 3.09683 & .029 & 0.678 & 16.0399 \\
\hline & $\begin{array}{l}\text { Unstructured } \\
\text { Doodling }\end{array}$ & $\begin{array}{l}\text { Structured } \\
\text { Doodling }\end{array}$ & -6.58974 & 3.09683 & .109 & -14.2707 & 1.0912 \\
\hline & & $\begin{array}{l}\text { Structured } \\
\text { Doodling }\end{array}$ & $-14.94872 *$ & 3.09683 & $<.0001$ & -22.4735 & -7.424 \\
\hline & Control & $\begin{array}{l}\text { Unstructured } \\
\text { Doodling }\end{array}$ & $-8.35897^{*}$ & 3.09683 & .024 & -15.8837 & -0.8342 \\
\hline & & Control & $14.94872 *$ & 3.09683 & $<.0001$ & 7.424 & 22.4735 \\
\hline & $\begin{array}{l}\text { Structured } \\
\text { Doodling }\end{array}$ & $\begin{array}{l}\text { Unstructured } \\
\text { Doodling }\end{array}$ & 6.58974 & 3.09683 & .106 & -0.935 & 14.1145 \\
\hline & & Control & $8.35897^{*}$ & 3.09683 & .024 & 0.8342 & 15.8837 \\
\hline \multirow[t]{2}{*}{ Bonferroni } & $\begin{array}{l}\text { Unstructured } \\
\text { Doodling }\end{array}$ & $\begin{array}{l}\text { Structured } \\
\text { Doodling }\end{array}$ & -6.58974 & 3.09683 & .106 & -14.1145 & 0.935 \\
\hline & $\begin{array}{l}\text { Structured } \\
\text { Doodling }\end{array}$ & Control & $14.94872 *$ & 3.09683 & $<.0001$ & 8.9564 & \\
\hline $\begin{array}{l}\text { Dunnett t } \\
{\text { (>control })^{\mathrm{b}}}^{\text {(n) }}\end{array}$ & $\begin{array}{l}\text { Unstructured } \\
\text { Doodling }\end{array}$ & Control & $8.35897^{*}$ & 3.09683 & .008 & 2.3667 & \\
\hline
\end{tabular}

Note. $*=$ the mean difference is significant at the .05 level.

Dunnet tests treat one group as the control, and compare all other groups against it. 


\section{Less Daydreaming Increased Recall Naturalistic Doodling}

100

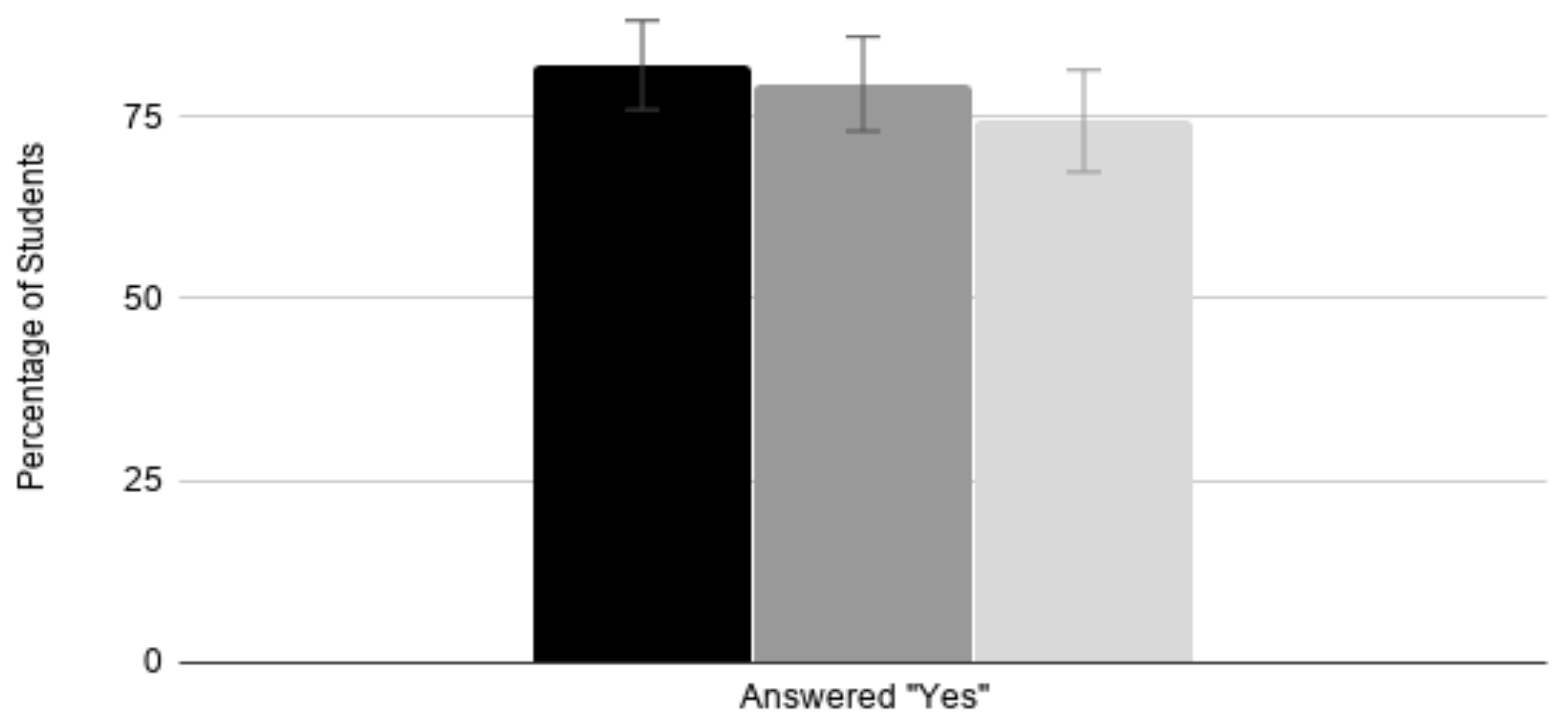

Figure 2. Percentage of students who answered "yes" to each phenomenon regarding their doodling experience.

Standard errors are represented in the figure by the error bars attached to each column.

The analysis of the results from the Post Doodling Experience are presented in Table 5. The answer "yes" equated to a score of 1 , while the answer "no" equated to a score of 0 . Based on the results, the average answer for whether students experienced less daydreaming/mind-wandering while doodling was 0.821 ( $\mathrm{SD}=0.061, \mathrm{p}<.001$ ), showing that doodling is correlated to less daydreaming and/or mind-wandering. This supports my second hypothesis that doodling would reduce the amount of daydreaming and/or mind-wandering experienced by students. Likewise, the average answer for whether students experienced increased recall ability after doodling was $0.795(\mathrm{SD}=0.065$, $\mathrm{p}<.001$ ), showing that doodling is correlated with increased recall ability. This is analogous to the experimental results, which showed increased quiz scores in the experimental doodling groups. Finally, the average answer for whether participants felt that they elicited a naturalistic form of doodling was $0.744(\mathrm{SD}=0.070, \mathrm{p}<.001)$, which supports my last hypothesis that doodling in an academic setting under normal circumstances would enable participants to doodle naturalistically without constraint.

Table 5. Questionnaire Analysis

\begin{tabular}{cccccc}
\hline Phenomenon & $n$ & Average & Sum & SD & Variance \\
\hline Less Daydreaming & 39 & 0.821 & 32 & 0.061 & 0.004 \\
Increased Recall & 39 & 0.795 & 31 & 0.065 & 0.004 \\
Naturalistic Doodling & 39 & 0.744 & 29 & 0.07 & 0.005
\end{tabular}

Note. The Post Doodling Questionnaire was created specifically for this study. In computing the averages for each phenomenon, the close-ended questions were set such that "no" is equated to a value of 0 and "yes" is equated to a value of 1 . 


\section{Discussion}

This study casts further light on the relationship between doodling and memory retention in high school students, with three principal findings. First, doodling showed higher academic performance and memory retention in students. This extends previous evidence from studies of junior high school students that doodling improved academic performance (Tadayon, Afhami, 2017). In Tadayon and Afhami's research, 54 female participants aged between 12 and 13 were given two quizzes in a control and experimental setting to assess the impact of doodling on their academic performance. In the experimental group, participants performed unstructured doodling on an A4 sheet while listening to a series of lectures. The doodlers outperformed the non-doodlers on the recall quiz by 6\% (mean diff.=.707). As presented, Tadayon and Afhami tested auditory recall with an unstructured doodling quiz. But in the current study, the effects of both unstructured and structured doodling on an auditory recall task were assessed in two separate experimental conditions. Similar studies conducted by Andrade (2010) and Boggs et al. (2017) also found that doodling as a whole improved memory retention. Andrade's study, which was limited to a control and structured doodling group, found that the latter recalled significantly more of the monitored (told to pay attention to) and incidental (not instructed to pay attention to) information. However, when Boggs et al. (2017) expanded upon Andrade's research by creating both an unstructured and structured doodling group, they found that those in the structured doodling group performed significantly better than the unstructured doodling group. In fact, those in the structured group outperformed all the other groups, except for note-taking. Furthermore, the unstructured doodling group scored the lowest out of all the experimental conditions. In the present study, although the structured doodling group scored the highest, unstructured doodling also proved to be beneficial to academic performance, with a score improvement of 8.359 from the control. This may be due to the amount of time that participants doodled. In Boggs' and Andrade's study, participants doodled for only five minutes and then were given a recall test. Contrastingly, in Tadayon and Afhami's study and the present study, participants were in their natural classroom setting, and were given a significant amount of time to doodle ( 40 minutes). This may have played a role in the nature of the doodles produced, as $74.4 \%$ of participants in the current study reported that their doodles were naturalistic and unforced. This brings me to my second finding that long periods of doodling encourage the spontaneous, automatic quality of naturalistic doodling. Naturalistic doodling would've allowed students to pay more attention to the main auditory task (lecture) rather than spending too many cognitive resources on their doodles, which would have withdrawn attention from the main task. On that note, the lower scores of the unstructured doodling group compared to the structured doodling group may be due to doodlers putting in more effort, attention, and/or thought into their doodles compared to those who are just shading in shapes (structured doodling condition). This hypothesis is consistent with previous studies that have shown a "bottleneck" effect (de Jong, 1993; McCann \& Johnston, 1992) where tasks requiring different competing cognitive resources (e.g., attention, short-term memory, decision making) can only be completed one at a time.

The third finding of this study was that doodling decreases the occurrence of daydreaming and/or mind-wandering in high school students. While this was hypothesized in previous studies, the added questionnaire, which reported that $82.1 \%$ of participants experienced less daydreaming while doodling, helped confirm this phenomenon. In both experimental groups (structured and unstructured doodling), participants experienced less daydreaming/mind-wandering, which would have enabled them to pay more attention to the main auditory task (lecture). This would've directly impacted their memory retention by increasing it, which was seen in the experimental findings as well as the questionnaire analysis. Doodling may have reduced daydreaming simply by adding a resource load to a rather undemanding task (Smallwood et al., 2007a), in which case increasing the demands of the primary task (requiring speeded responses, for instance) would have had a similar effect. In addition, doodling may have reduced daydreaming by selectively loading central executive resources. Although doodling is itself relatively undemanding of executive resources, being self-paced, repetitive, and involving little controlled processing such as performance monitoring or inhibition of irrelevant information, the combination of doodling with the auditory task (lecture) should have engaged executive resources needed to coordinate verbal and visuo-spatial short-term memory (Baddeley, 1996). This is synchronous with findings in previous studies regarding attention that the presence of a concurrent task such as doodling helps to maintain some basal level of attention necessary for a simple task such as an auditory lecture (Roche et al. 2007). Since doodling is low in stimulation levels, it blocked the natural diminution of resources by providing additional stimulation, resulting in enhanced learning.

\subsection{Conclusion and Future Implications}

Results from this study offer the first evidence that both structured and unstructured doodling may be associated with increased recall ability in high school students. Many students who may have used doodling as a means to eliminate external distractions may have been misinformed that it deteriorates learning. Many teachers continue to 
believe that doodling is a sign of distraction in students, but it has actually shown to be advantageous to academic performance. Therefore, an implication of the results in the current study include informing teachers about the benefits of doodling as a learning assistive technique in students.

It is significant for future researchers to further investigate the factors involved in the relationship between doodling and recall ability, such as the possibility of order effects, how it impacts long-term memory storage, or the physiological counterparts involved in doodling that help memory retention. In the study analysis, doodling was found to decrease levels of daydreaming in students, which may have other implications outside the realm of high school students. Future investigators of this subject should analyze how doodling can be used to counteract learning anxiety or other types of learning disabilities, such as ADHD or dyslexia. In individuals with learning disabilities, attention "deficit" increases with the length, familiarity, and repetitiveness of a task (Zentall, 2006). Using an activity that requires a sense other than that required for the primary task, such as doodling, may help enhance performance in children with learning disabilities.

The significant results of this study have demonstrated that structured and unstructured doodling can potentially enhance recall ability in academic settings. Further research in the field may provide insight into new learning patterns involving doodling to maximize students' academic performance.

\section{Acknowledgements}

I would like to express my deepest gratitude to Mr.Rolofson, for helping me recruit participants and collect data for this study. I would also like to thank those who reviewed and offered valuable technical suggestions for my paper, for their useful critiques that helped me produce the best version of this paper.

Finally, I would like to thank my wonderful father for enthusiastically supporting me throughout this endeavor, and my mother for pushing me to do my best.

\section{References}

Andrade, J. (2009). What does doodling do? Applied Cognitive Psychology, 24, 100-106. https://doi.org/10.1002/acp.1561

Baddeley, A. D. (1996). Exploring the central executive. Quarterly Journal of Experimental Psychology, 49A, 5-28. https://doi.org/10.1080/713755608

Boggs, J.B., Cohen, J.L. \& Marchand, G. C. (2017). The Effects of Doodling on Recall Ability. Psychological Thought, 10(1), 206-216. https://doi.org/10.5964/psyct.v10i1.217

Burger, J., Lee, E. \& Rust, A. (2018). The Effects of Doodling on Performance in a Memory Task. The University of Minnesota Undergraduate Journal of Psychology, 17, 1-5.

Chan, E. (2012). The Negative Effect of Doodling on Visual Recall Task Performance. Department of Psychology, University of British Columbia.

Cloud, J. (2009, February 26). Study: Doodling Helps You Pay Attention. Retrieved from http://content.time.com/time/health/article/0,8599,1882127,00.html

Creswell, J. W. (2003). Research design: Qualitative, quantitative, and mixed methods approaches (2nd ed.). Thousand Oaks, CA: Sage.

Jacob, B. A. (2002). Where the boys aren't: Non-cognitive skills, returns to school and the gender gap in higher education. Economics of Education Review, 21(6), 589-598. https://doi.org/10.1016/S0272-7757(01)00051-6

Mason, M. F., Norton, M. I., Van Horn, J. D., Wegner, D. M., Grafton, S. T. \& Macrae, C. N. (2007). Wandering minds: the default network and stimulus-independent thought. Science (New York, N.Y.), 315(5810), 393-395. https://doi.org/10.1126/science.1131295

McMillan, R. L., Kaufman, S. B. \& Singer, J. L. (2013). Ode to positive constructive daydreaming. Frontiers in psychology, 4, 626. https://doi.org/10.3389/fpsyg.2013.00626

Pillay, S., Dr. (2016, December 15). The "thinking" benefits of doodling. Retrieved October 14, 2019, from https://www.health.harvard.edu/blog/the-thinking-benefits-of-doodling-2016121510844

Roche, R.A.P., Commins, S. \& Agnew, F. (2007). Concurrent task performance enhances low-level visuomotor learning. Perception \& Psychophysics, 69, 513-522, https://doi.org/10.3758/BF03193908

Schott, G. (2011). Doodling and the default network of the brain. The Lancet, 378(9797), 1133-1134. https://doi.org/10.1016/S0140-6736(11)61496-7 
Shellenbarger, S. (2014, July 29). The Power of the Doodle: Improve Your Focus and Memory. Retrieved March 16 , 2020 ,

https://www.wsj.com/articles/the-power-of-the-doodle-improve-your-focus-and-memory-1406675744

Singh, T. \& Kashyap, N. (2015). Does Doodling Effect Performance: Comparison Across Retrieval Strategies. Psychol Stud, 60, 7-11, https://doi.org/10.1007/s12646-014-0293-3

Tadayon, M. \& Afhami, R. (2017). Doodling Effects on Junior High School Students' Learning. International Journal of Art \& Design Education, 36(1), 118-125. https://doi.org/10.1111/jade.12081

Teasdale, J.D., Dritschel, B.H. \& Taylor, M.J. (1995). Stimulus-independent thought depends on central executive resources. Memory and Cognition, 23, 551-559, https://doi.org/10.3758/BF03197257

Zentall, S. S. (2006). Adhd and education: foundations, characteristics, methods, and collaboration. Pearson/Merrill Prentice Hall.

\section{Notes}

Note 1. The stream of consciousness that detaches from current external tasks when attention drifts to a more personal and internal direction.

Note 2. The state of being physiologically alert, awake, and attentive.

Note 3. A procedure in experimental neuropsychology that requires an individual to perform two tasks simultaneously.

Note 4. In the context of this field, "optimal levels of arousal" pertains to a psychological construct referring to a level of mental stimulation at which physical performance, learning, or temporary feelings of wellbeing are maximized (Smith 1990).

Note 5. In unstructured doodling, participants must actively decide what to doodle; they are free to doodle anything they wish.

Note 6. In structured doodling, the participants' drawings are organized, such as shading in shapes. 


\section{APPENDIX A: Instructions for Experimental Conditions}

\section{Structured Doodling Condition Instructions}

Hello students! If you submitted your consent form allowing you to participate in the following research study, then please raise your hand. You will receive a structured doodling sheet if you agreed to participate. If you are not participating in the study, please be respectful and proceed with the lesson as you normally would.

The participating students are instructed to fill in their seat number and age in the two blanks on the top left hand corner of the doodling sheet. Throughout the lecture, participating students are suggested to shade in the shapes on the doodling sheet while listening to the lecture, but they are not obligated to do so. They can shade using a pencil, pen, marker, or any writing utensil of their choice. At the end of the lecture, participating students shall return their doodling sheets to the teacher.

It is to be noted that students are recommended to only shade in the shapes on the front of their doodling sheet. Additionally, please refrain from writing any words or letters on the doodling sheet other than the blanks indicated for your seat number and age. Enjoy your doodling time!

\section{Unstructured Doodling Condition Instructions}

Hello students! If you submitted your consent form allowing you to participate in the following research study, then please raise your hand. You will receive a plain, white A4 sheet if you agreed to participate. If you are not participating in the study, please be respectful and proceed with the lesson as you normally would.

The participating students are instructed to fill in their seat number and age in the two blanks on the top left hand corner of the blank sheet. Throughout the lecture, participating students are suggested to doodle freely on the A4 sheet while listening to the lecture, but they are not obligated to do so. They can shade using a pencil, pen, marker, or any writing utensil of their choice. At the end of the lecture, participating students shall return their A4 sheets to the teacher.

It is to be noted that students there is no restriction on what students can doodle and the amount of doodles that they can make. Students are free to doodle in whatever manner they choose. However, please refrain from writing any words or notes on the A4 sheet. Enjoy your doodling time! 


\section{APPENDIX B: Structured Doodling Sheet}

Participants in the structured doodling group were provided with a modified copy of the "Structured Doodling Sheet" used by Boggs et al. (2017). The two modifications were the blanks for the participants' seat numbers and ages. See the image below for reference:

Seat Number:

How old are you as of today?
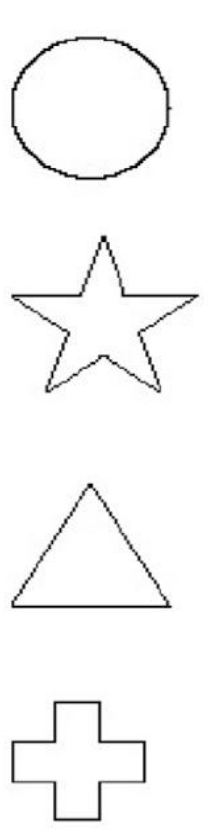

$\sqrt{1}$

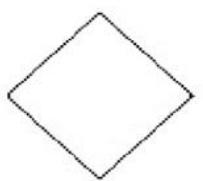

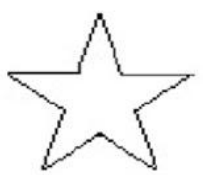

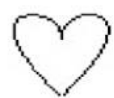<smiles>C1CCCCCCCC1</smiles><smiles>C1CCCCCCCCCCCC1</smiles>
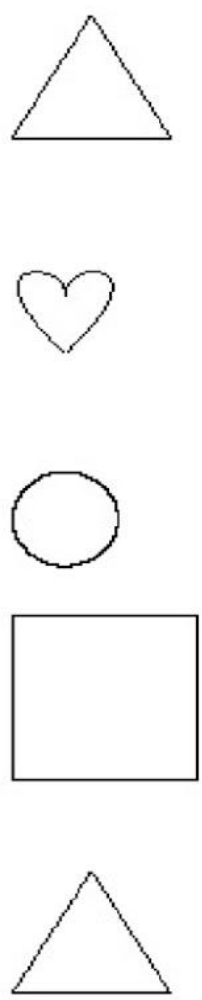
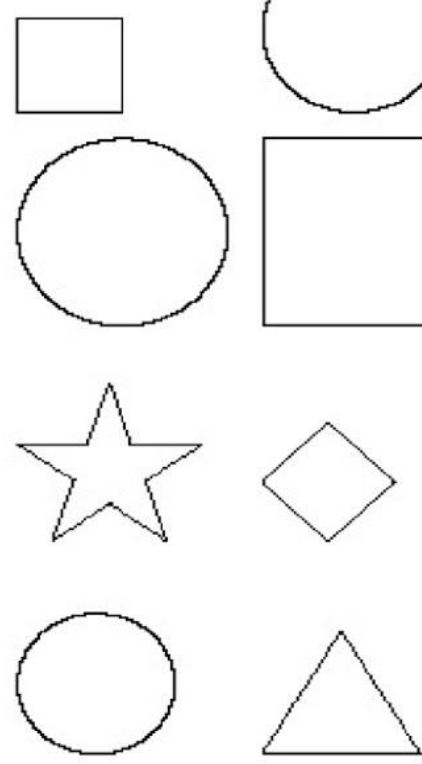<smiles>C1CCCCC1</smiles>
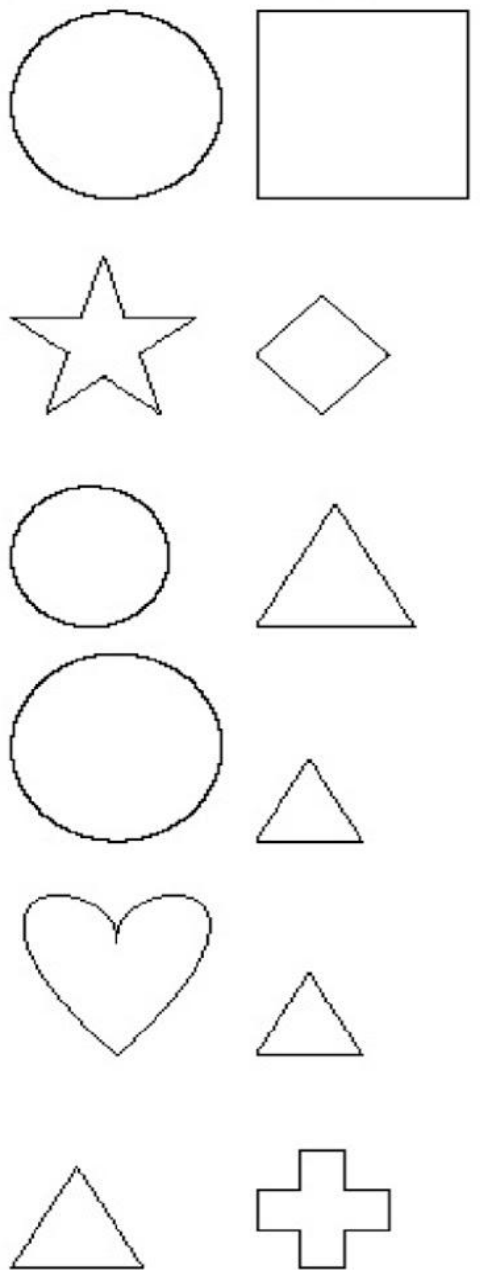
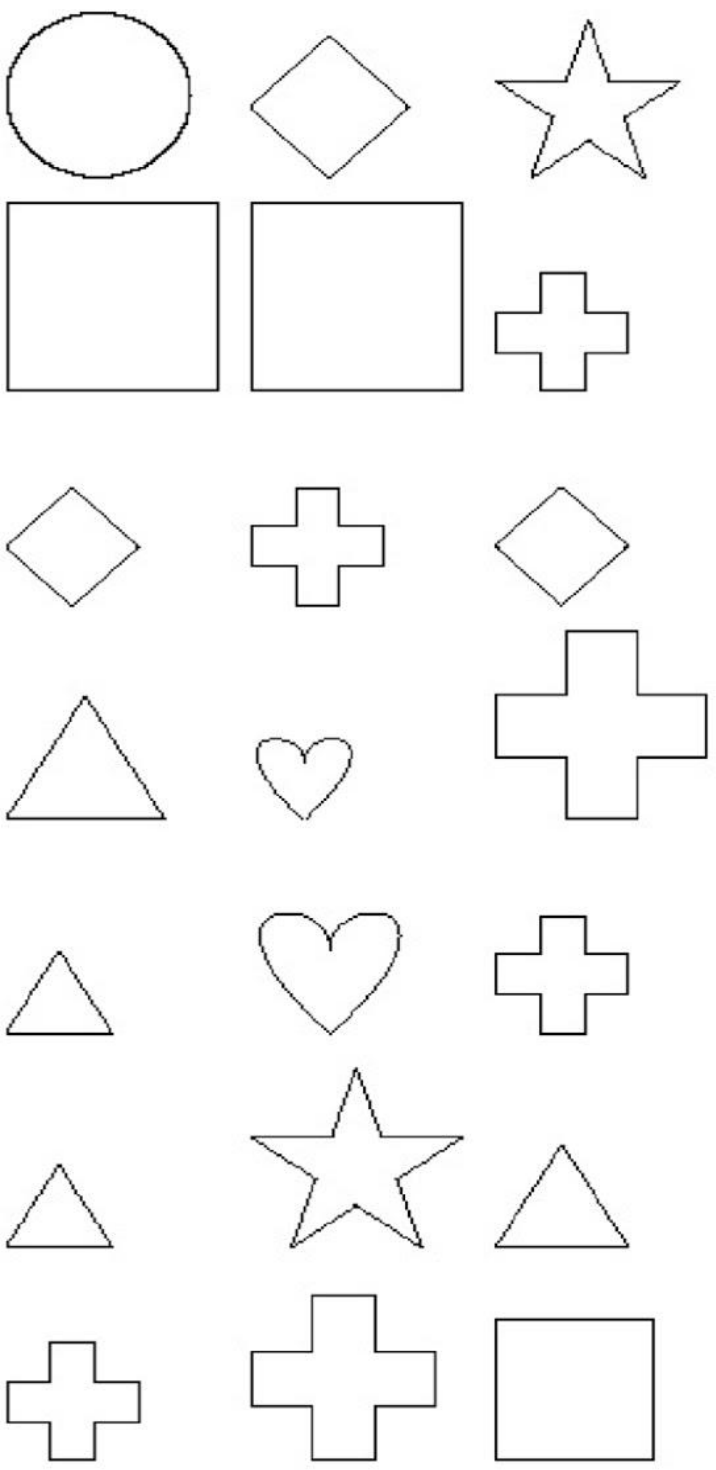


\section{APPENDIX C: Questionnaire}

The following questionnaire was created specifically for the present study. It was used to analyze participants' doodling experience in terms of levels of daydreaming, recall ability, and nature of doodling. There were three close-ended questions with the answer choices "yes" and "no."

\section{Post Doodling Experience Questionnaire}

This survey is intended for participants of the research experiment conducted in AP U.S. History.

1. Did you find that you experienced less daydreaming and/or mind-wandering when you doodled during the lecture?

Answer Choices: Yes/No

1. Do you feel that your doodles occurred in a naturalistic manner rather than forceful manner?

Answer Choices: Yes/No

1. Did you feel that doodling during lecture increased your recall ability of the information taught?

Answer Choices: Yes/No

\section{Copyrights}

Copyright for this article is retained by the author(s), with first publication rights granted to the journal.

This is an open-access article distributed under the terms and conditions of the Creative Commons Attribution license (http://creativecommons.org/licenses/by/4.0/). 